\title{
Языковая политика в аспекте микро- и макросоциолингвистики
}

Татьяна Кортава

DOI: 10.30547/mediaalmanah.6.2020.134143

(c) Кортава Татьяна Владимировна член-корреспондент РАО, профессор, доктор филологических наук, заведующая кафедрой русского языка для иностранных учащихся естественных факультетов филологического факультета МГУ имени М.В. Ломоносова, вице-президент Российского общества преподавателей русского языка и литературы (РОПРЯЛ) и Международной ассоциации преподавателей русского языка и литературы (МАПРЯЛ), проректор - начальник Управления по работе с талантливой молодежью МГУ имени М.В. Ломоносова

(г. Москва, Россия), tkortava@mail.ru
История российско-французских гуманитарных связей имеет немало ярких страниц. Научные и практические контакты педагогов и филологов никогда не прерывались, проводятся кросс-культурные исследования, растет интерес к российскофранцузским культурно-просветительским мероприятиям.

Полагаю, что цель нашего семинара - обсуждение новых направлений для совместной работы в области внутренней и внешней языковой политики. Сразу отмечу, что объединение усилий принципиально важно и чрезвычайно перспективно, учитывая, прежде всего, наше единство в отношении к государственному языку.

В середине XIX века знаменитый французский историк Жюль Мишле написал: «История Франции начинается с французского языка». Примерно в это же время выдающийся русский этнограф, славист, один из основоположников методики преподавания отечественной словесности академик Измаил Иванович Срезневский заметил: «Язык и нация - единица неразделимая». Эти идеи определяют стратегическое единство микросоциолингвистических и макросоциолингвистических подходов в государственной языковой политике России и Франции.

Сегодня, в условиях нарастающего напора глобализации, обсуждение проблем 


\section{La politique linguistique sous son aspect micro- et macrosociolinguistique}

\section{Tatiana Kortava}

\section{(c) Kortava Tatiana}

membre correspondant de l'Académie de l'enseignement de Russie, professeur, docteur en philosophie, titulaire de la chaire de russe comme langue étrangère pour les étudiants des départements de sciences exactes de l'Université d'État de Moscou Lomonossov, vice-présidente de la Société russe des professeurs de langue et de littérature russes (Roprial) et de l'Association internationale des professeurs de langue et de littérature russes (Maprial), vice-rectrice et chef de la Direction des jeunes talents de l'Université d'État de Moscou Lomonossov.

(Moscou, Russie), tkortava@mail.ru

L'histoire des relations franco-russes dans le domaine des sciences humaines a connu un certain nombre de pages glorieuses. Les contacts scientifiques et pratiques entre les enseignants et les linguistes ne se sont jamais relâchés, des études culturelles croisées sont organisées, et l'intérêt pour les rencontres culturelles franco-russes ne cesse de croître.

Je suppose que l'objectif de notre séminaire est de discuter des nouvelles orientations pour notre travail mené en commun dans le domaine de la politique linguistique intérieure et extérieure. Je tiens à noter tout d'abord qu'il est essentiel d'unir nos efforts et que cela ouvre des perspectives compte tenu, avant tout, de notre unité dans notre rapport envers la langue officielle.

Au milieu du XIXe siècles le célèbre historien Jules Michelet écrivait : «L'histoire de France commence avec la langue française ». À peu près à la même époque l'académicien, ethnologue russe et spécialiste du monde slave Izmaïl Sreznevsky, un des fondateurs de la méthode d'enseignement de la langue russe notait : " La langue et la nation sont une unité indissociable ». Ces idées définissent l'unité stratégique des approches microsociolinguistiques et macrosociolinguistiques dans la politique linguistique de la Fédération de Russie et de la France.

Aujourd'hui, dans le contexte de mondialisation pressante, discuter des problèmes d'édification de la langue dans le cadre du dialogue culturel franco-russe est d'une grande actualité.

Si on lit attentivement l'intervention du président français Emmanuel Macron du 20 mars 2018 à l'Académie française à l'occasion de la Journée internationale de la Francophonie où il définit 30 mesures visant au renforcement du rôle du français, et le discours du président russe Vladimir Poutine du 5 novembre 2019 donné lors de la réunion du Conseil de la langue russe, il devient évident que nous avons une unité de stratégie et de conception sur le rôle fondamental de la langue d'État dans les conditions de maintien de la diversité culturelle et linguistique.

L'expression de " politique linguistique » est née en France et son expérience en matière de réalisation, à partir du XIVe siècle, mérite d'être étudiée de près. La loi sur le français soigneusement élaborée dans laquelle les mondialistes voient du protectionnisme et du purisme reflète le principe fondamental «État-nationlangue ». Le français peut être qualifié de religion officielle de la France, de sym- 
языкового строительства в рамках российско-французского общегуманитарного диалога приобретает особую актуальность.

Если внимательно прочитать выступление Президента Франции Эмманюэля Макрона 20 марта 2018 г. во Французской Академии в Международный день франкофонии, где он определил 30 мер для усиления роли французского языка, и речь Президента Российской Федерации В.В. Путина 5 ноября 2019 г. на заседании Совета по русскому языку становится очевидным стратегическое единство наших взглядов на основополагающую роль государственного языка при условии сохранения культурно-языкового разнообразия.

Термин «языковая политика» родился во Франции, поэтому опыт ее реализации, начиная с XIV века, заслуживает внимательного изучения. Тщательно разработанный «Закон о французском языке», в котором глобалисты усматривают протекционизм и пуризм, отражает основополагающий принцип «государство - нация - язык». Французский язык можно назвать государственной религией Франции, ее символом, непоколебимым во времени и пространстве. Все попытки косметических орфографических реформ государственного языка, начиная с XVI века, встречают шквал протестов и терпят фиаско.

Россия же на пути к современному письму пережила смену устава полууставом и скорописью и три орфографические реформы. К слову, интерес к изменению орфографии не угасает и в наши дни.

Россия и Франция - страны, обладающие значительным культурно-языковым разнообразием, но они никогда не придерживались американской стратегии melting pot («плавильного котла»), не стремились к ассимиляции языков и народов.

Во Франции 75 языков, включая заморские владения.

Закон «О языках народов РФ» 1991 г. дает право республикам устанавливать, наряду с общегосударственным - русским, свой государственный язык. Таким образом, на сегодняшний день в нашей стране их 38. В России 277 языков и диалектов, более 150 коренных народов. При этом 98,2\% населения владеет государственным языком РФ. Закон «О государственном языке Российской Федерации» был принят в 2005 г. Языковая ситуация в нашей стране осложняется дисперсным расселением, в отличие от компактного, характерного для носителей региональных и заморских языков Франции.

Совместная работа над совершенствованием законодательства в области внутренней языковой политики, особенно в части статуса региональных или родных языков в сфере образования, будет полезна обеим сторонам.

В Российской Федерации действует многокомпонентная модель государственной внутренней языковой политики, основным принципом которой является сохранение этнокультурной идентичности на местном уровне при прочном осознании общероссийской гражданской идентичности.

В РФ существуют:

1) языки с развитой филологической традицией (татарский, башкирский, якутский, чувашский);

2) младописьменные, для которых алфавиты были созданы в 1920-1930 гг. (мордовский, марийский, ненецкий и др.);

3) новописьменные, которые получили алфавит в 1990 гг. (вепский);

4) языки с возобновленной письменностью (карельский, цахурский);

5) бесписьменные языки (тиндинский).

Особенно тревожит судьба языков коренных малочисленных народов Сибири, Севера и Дальнего Востока. И не только в этом году, который Генеральной Ассамблеей ООН объявлен Международным годом языков коренных народов. Еще в 1920 гг. в Ленинграде был создан Институт народов Севера.

Для координации действий на внутрироссийском пространстве в 2014 г. Указом 
bole intangible dans le temps et dans l'espace. Toutes les tentatives de réformes cosmétiques de l'orthographe de la langue officielle, depuis le XVle siècle, ont été accueillies par des avalanches de protestations et ont échoué.

La Russie sur la voie menant à sa forme actuelle a connu un remplacement de la charte par une demie-charte et de la notation écrite, et trois réformes de l'orthographe. D'ailleurs l'intérêt pour une modification de l'orthographe ne s'évanouit pas non plus de nos jours.

La Russie et la France sont des pays pourvus d'une grande diversité linguistique mais elles n'ont jamais suivi la stratégie américaine du melting pot, elles n'ont pas cherché l'assimilation des langues et des peuples.

On compte en France 75 langues, y compris celles des territoires d'outre-mer.

La loi « Sur les langues des peuples de la Fédération de Russie » de 1991 accorde le droit aux républiques entrant dans la composition de la Fédération d'établir, à parité avec la langue officielle qu'est le russe, leur propre langue officielle. C'est ainsi qu'elles sont au nombre de 38 aujourd'hui en Russie. On compte dans le pays 277 langues et dialectes et plus de 150 peuples autochtones. La langue russe officielle est maîtrisée par 98,2\% de la population. La loi « Sur la langue officielle de la Fédération de Russie " a été adoptée en 2005. La situation linguistique en Russie est rendue complexe par la dispersion de la population alors qu'en France elle est compacte, notamment dans le cas des locuteurs des langues régionales et d'outre-mer.

Les travaux menés en commun sur le perfectionnement de la législation en matière de politique linguistique intérieure, notamment vis-à-vis du statut des langues régionales ou maternelles dans le domaine de l'enseignement seront utiles aux deux parties.

En Russie c'est un modèle complexe de politique linguistique intérieure qui opère et son principe essentiel est le maintien de l'identité ethnoculturelle au niveau local simultanément à une conscience d'identité citoyenne russe générale.

En Fédération de Russie existent:

1) des langues à tradition philologique développée (tatare, bachkire, yakoute, tchouvache) ;

2) des langues à écriture récente pour lesquelles des alphabets ont été créés dans les années 1920-1930 (mordve, mari, nénètse, etc.) ;

3) des langues à écriture très récente qui ont bénéficié d'un alphabet dans les années 1990 (vepse) ;

4) des langues à écriture restituée (carélien, tsakhoure) ;

5) des langues uniquement orales (tindi).

Le sort des langues de peuples autochtones à population réduite de Sibérie, du Grand nord et de l'Extrême-Orient est particulièrement préoccupant. Cela ne date pas de cette année, 2019, que l'Assemblée générale de l'ONU a proclamée Année internationale des langues autochtones, dès les années 1920 à Léningrad avait été fondé l'Institut des peuples du Grand Nord.

Pour coordonner les actions au niveau intérieur un décret présidentiel avait institué en 2014 un Conseil de la langue russe, dirigé par Vladimir Tolstoï, et en octobre 2018 un autre décret présidentiel avait mis en place la Fondation de préservation et d'étude des langues des peuples autochtones de la Fédération de Russie. Le professeur Olga Vassilieva, ministre de l'Instruction publique, dirige la 
Президента РФ создан Совет по русскому языку, которым руководит Владимир Ильич Толстой, в октябре 2018 г. указом Президента учрежден Фонд сохранения и изучения родных языков народов РФ. Министр просвещения профессор Ольга Юрьевна Васильева руководит Межведомственной комиссией по русскому языку. При Министерстве просвещения работает Институт родных языков.

Государство прилагает титанические усилия для сохранения языков, которые находятся под угрозой исчезновения. Это глобальная проблема, которая обусловлена не только демографическими сдвигами, но и падением уровня национального самосознания, потерей языка в семейном общении и ослаблением генетической мотивации к сохранению лингвистических корней. Эта актуальная для обеих стран проблема носит комплексный характер, и поиск возможных путей ее решения должен осуществляться на междисциплинарном уровне с учетом достижений лингводидактических и этнопсихолингвистических исследований.

Ключевой сферой сохранения и развития языка является образование. Наши страны, начиная с XIX века, накопили колоссальный опыт по введению в систему образования региональных или родных языков. Почти одновременно, во второй половине XIX века, были проведены образовательные реформы министра просвещения Франции Жюля Ферри и министра внутренних дел Российской империи графа Дмитрия Андреевича Толстого по внедрению в систему начального образования региональных или родных языков. В сравнительно-историческом аспекте результаты этих реформ не были изучены. Заслуживает обсуждения проблема обучения билингвов, мигрантов, соотечественников, живущих за рубежом, модели «гнездового обучения" и методики «полного погружения», обучения в кочевых условиях, а также модели поликультурной школы. Все это разные методические сценарии.
Необходимо также активизировать взаимное преподавание французского и русского языков. Для методики преподавания живых языков очень важно вернуться к фундаментальным работам Эмиля Бенвениста и Льва Владимировича Щербы, перечитать «Малую грамматику русского языка» Люсьена Теньера, изданную в 1934 г. и отражающую преемственность идей русской синтаксической школы Алексея Александровича Шахматова.

Без фундаментальных междисциплинарных научных исследований достичь успеха в лингводидактической сфере очень трудно. Если мы сможем организовать диалог с участием этнографов, психологов и социологов, то он подаст пример сохранения культурно-языкового разнообразия на нашей планете.

Для русистов очень важен опыт работы Генеральной комиссии по терминологии и неологии, которая существует во Франции с 1997 г. и тесно связана с ведомственными комиссиями различных министерств. Ее цель - привлечение широкой общественности к обсуждению проблем развития государственного языка. Кстати, этот опыт успешно использует Исландия. Термины, предлагаемые Генеральной комиссией, передаются на утверждение Французской Академии. После одобрения неологизмы публикуются в Официальном бюллетене Французской Республики и становятся обязательными для государственных служб и образцом для граждан. Поиск французских эквивалентов для англоязычных терминов не только показывает возможности государственного регулирования языка, но и открывает новый источник для самообогащения французского языка.

В 2001 г. было создано Национальное управление по продвижению французского языка и языков Франции. Его главная задача - вовлечение населения в процесс языкового регулирования. Для широкого обсуждения проблем государственного языка существует интернет-сайт. 
Commission interministérielle de la langue russe et un Institut des langues autochtones fonctionne auprès du ministère de l'Instruction publique.

L'État fait des efforts titanesques pour préserver les langues menacées de disparition. C'est un problème à l'échelle mondiale qui s'explique non seulement par les évolutions démographiques mais aussi la baisse du niveau de conscience nationale, la perte de la langue dans le cercle familial et l'affaiblissement de la motivation génétique pour le maintien des racines linguistiques. Ce problème, d'actualité pour de nombreux pays, revêt un caractère complexe et les recherches de solutions éventuelles doivent se faire au niveau interdisciplinaire sur la base des résultats obtenus en matière d'enseignement des langues et d'ethno-socio-linguistique.

Le domaine clef de maintien et de développement de la langue est l'enseignement. Nos pays, à partir du XIXe siècle, ont accumulé une expérience colossale dans le domaine de l'inclusion des langues régionales ou natales dans le système d'enseignement. Presque simultanément, dans la deuxième moitié du XIXe siècle, des réformes ont été menées par le ministre de l'Instruction publique Jules Ferry et le ministre de l'intérieur de l'Empire russe, le comte Dmitri Tolstoï, pour inclure dans l'enseignement primaire les langues régionales ou natales. Les résultats de ces réformes n'ont pas fait l'objet d'analyses comparatives et historiques. Le problème de l'apprentissage pour les bilingues, les migrants, les expatriés, des modèles d'apprentissage en milieu restreint et des méthodes d'« immersion totale », d'apprentissage en milieu nomade et aussi d'école multiculturelle méritent aussi de faire l'objet d'une étude. Tout cela relève de schémas méthodiques différents.

Il est nécessaire aussi d'activer l'enseignement réciproque du français et du russe. Pour la méthode d'enseignement des langues vivantes il est très important de revenir aux travaux fondamentaux d'Émile Benvéniste et Lev Chtcherba, de relire la Petite grammaire russe de Lucien Tesnière publiée en 1934 et qui reflète l'héritage des idées de l'école syntaxique russe d'Alexeï Chakhmatov.

Sans recherches scientifiques fondamentales interdisciplinaires il sera très difficile de parvenir à des résultats dans le domaine de l'enseignement des langues. Si nous pouvons organiser un dialogue avec la participation d'ethnologues, de psychologues et de sociologues, alors non seulement il s'avérera utile pour nos deux pays mais il servira d'exemple de préservation de la diversités des langues et cultures sur notre planète.

Pour les spécialistes de la langue russe l'expérience de la Commission générale de terminologie et de néologie qui existe en France depuis 1997 et est étroitement liée à des commissions de différents ministères est importante. Son objectif est d'impliquer autant que possible le public dans les discussions sur les problèmes de développement de la langue officielle. C'est d'ailleurs une expérience qui a été largement mise en pratique en Islande. Les termes proposés par la Commission générale sont transmis à l'Académie française pour validation. Après approbation les néologismes sont publiés au Journal officiel de la République française, leur emploi devient obligatoire pour les services de l'État et ils sont la référence pour les Français. La recherche d'équivalents français aux termes anglo-saxons montre qu'un contrôle officiel de la langue par l'État est possible mais aussi ouvre de nouvelles sources d'enrichissement de la langue. 
Механизм интерактивного взаимодействия с обществом в области внутренней языковой политики в РФ пока только разрабатывается и степень вовлеченности общества в обсуждение вопросов государственного языка в РФ ниже, чем во Франции. На это нам следует обратить внимание и изучить опыт наших французских коллег.

В 1966 г. Шарль де Голль при поддержке Жоржа Помпиду создал Высший комитет по защите и распространению французского языка. Неутомимая деятельность институтов Франкофонии, рассеянных по всему миру, не нуждается в комплиментах, а вызывает восхищение и желание подражать. Механически масштабировать эту систему невозможно, но тщательно изучить необходимо.

Почти одновременно, в 1967 г., создан Международный Совет французского языка, в который вошли представили всех франкоязычных стран, и в 1968 г. в Париже состоялся учредительный съезд Международной ассоциации преподавателей русского языка и литературы (МАПРЯЛ), президентом которой сейчас является советник Президента РФ Владимир Ильич Толстой. Так что Париж можно назвать родиной всех русистов мира.

Мы активно развиваем сеть российских центров науки и культуры и сеть кабинетов «Русский мир». Хотелось бы высказать одно пожелание: необходимо расширить сценарий образовательных и культурнопросветительских мероприятий, например, на семинары по повышению квалификации учителей приглашать искусствоведов, библиотекарей, музыковедов, режиссеров и сценаристов. Последние социологические опросы молодежи, изучающей русский язык за рубежом, показывают, что в рейтинге мотивов для выбора иностранного языка на первом месте - кино, далее - музыка, потом литература. Поэтому просветительские и образовательные мероприятия должны носить комплексный характер.
В условиях современной агрессивной глобализации у нас есть общая серьезная проблема - выдавливание французского и русского языков из сферы функционирования как мировых. Бороться с этим трудно, но нужно действовать сообща, по заранее разработанному плану, и не столько на политической сцене.

«Лингвистический империализм», его причины, последствия и пути замедления это еще одна тема для междисциплинарного обсуждения. Хотя термин появился в научном обороте в 90-е годы прошлого века, этот негативный для наших языков процесс начался полвека назад, еще в 1968-1969 гг., что зафиксировано в отчете Британского Совета тезисом: Britain's real black gold is not North Sea oil, but English language («Настоящее черное золото Британии не нефть Северного моря, а английский язык»).

Языковая унификация имеет катастрофические последствия не только для культурно-языкового разнообразия. Труды Вильгельма фон Гумбольдта, Фердинанда де Соссюра, Бодуэна де Куртенэ учат, что каждый язык формирует особые мыслительные сценарии, которые приводят к неожиданным, судьбоносным для всего человечества открытиям. Никто пока не постиг тайну французской и русской научной, музыкальной, художественной гениальности, их взаимопроникновения и взаимопостижения.

Вчера в Московском университете на Международном конгрессе, посвященном культурным кодам, прозвучала интересная мысль: искусственный интеллект тоже будет национально-ориентированным, потому что он будет отражать культурный код создателя.

Увлечение искусственным интеллектом, организация единого научно-образовательного пространства с помощью английского языка - linqua franca, обязательное требование для рейтингов вузов публиковать научные результаты на английском 
En 2001 a été créé la Délégation générale à la langue française et aux langues de France dont la mission principale consiste à faire participer la population au règlement des questions liées à la langue. Un site internet est dédié aux discussions portant sur la langue officielle.

Le mécanisme d'échanges interactifs avec la société dans le domaine de la politique de la langue en Fédération de Russie n'en est qu'au stade de l'élaboration et le degré d'implication de la société dans les discussions sur ce sujet en Russie est plus faible qu'en France. Il convient donc d'y être attentif et d'étudier l'expérience de nos collègues français.

En 1966 Charles De Gaulle, avec le soutien de Georges Pompidou, avait créé le Haut comité pour la défense et l'expansion de la langue française. L'activité inlassable des institutions de la Francophonie répandues partout dans le monde ne nécessite pas de compliments mais suscite l'enthousiasme et la volonté de les imiter. Il est impossible de donner une estimation chiffrée de ce système mais il est indispensable de l'étudier en détail.

Presqu'en même temps, en 1967, a été créé le Conseil international de la langue française qui regroupait tous les pays francophones et en 1968 eut lieu à Paris le congrès fondateur de l'Association internationale des professeurs de langues et de littérature russes (MAPRIAL) présidé aujourd'hui par Vladimir Tolstoï, conseiller du président de la Fédération de Russie. Si bien qu'on peut qualifier Paris de patrie de tous les spécialistes du russe du monde.

Nous développons activement le réseau de Centres de Russie pour la science et la culture et celui des agences du " Monde russe ». Je voudrais exprimer un vœu : étendre le scénario des rencontres culturelles et de formation, par exemple, aux séminaires de formation des enseignants en invitant des historiens de l'art, des bibliothécaires, des musiciens, des metteurs en scène, des réalisateurs et des scénaristes.

De récents sondages montrent que parmi les raisons pour lesquelles les jeunes qui étudient le russe à l'étranger ont choisi d'étudier cette langue ils placent au premier rang le cinéma, puis la musique, et ensuite la littérature. Par conséquent, les mesures liés à l'enseignement et l'information doit revêtir un caractère global.

Dans les conditions de mondialisation agressive nous sommes confrontés aussi à un problème grave qui nous est commun : le français et le russe se trouvent chassés du champ de la pratique comme langues mondiales. Il est difficile de lutter contre ce phénomène mais nous pouvons agir de concert, selon un plan validé au préalable, et pas seulement sur la scène politique.

L'«impérialisme linguistique ", ses raisons, ses conséquences et les moyens de le retarder constituent également un thème nécessitant qu'on y réfléchisse à l'échelle interdisciplinaire. Bien que le terme soit apparu dans la langue scientifique dans les années 1990, ce processus négatif pour nos langues a commencé il y a un demi-siècle, dès les années 1968-1969, ce qui a été entériné par le British Council via l'adage selon lequel « Britain's real black gold is not North Sea oil, but English language ». En cinquante ans nous avons vu qu'il en est effectivement ainsi.

L'unification linguistique entraîne des conséquences catastrophiques non seulement pour la diversité culturelle et linguistique. Les ouvrages de Wilhelm von Humboldt, de Ferdinand de Saussure, de Baudouin de Courtenay nous ap- 
языке - все это приведет к оскудению культурно-языкового ландшафта Земли, обеднению научной мысли, творцом которой является естественный интеллект человека. Для примера полезен опыт Японии, где все значимые научные статьи сначала публикуются в японских журналах на японском языке.

Кстати, замечу, что от галломании в первой трети XIX века мы получили прекрасно отработанный эпистолярный стиль и шире - «золотой век русской литературы». A linqua franca пока ведет только к засорению русского языка оправданными заимствованиями.

С горечью хочу обратить внимание российских участников на то, что иногда приходится присутствовать на конференциях, которые проводятся на территории Российской Федерации, а рабочий язык - ломаный английский.

Россия и Франция совместными усилиями должны настойчиво показывать миру коммерческую суть глобализации, использовать образовательные и просветительские платформы друг друга для популяризации французского и русского языков в макросоциолингвистическом пространстве, шире применять возможности цифровизации для повышения мотивации к взаимному изучению языков в молодежной среде.
Особого внимания российских коллег заслуживает полезный опыт библиотек Франции и страницы Gallica на сайте Библиотеки Конгресса США с бесплатным доступом к литературе на французском языке.

В 2000 г. была создана Международная франкоязычная сеть языкового строительства для развития франкоязычного контента в сети Интернет. У нас тоже есть проекты такого рода, которые направлены на расширение русскоязычного контента в сети Интернет, и это очень интересная тема для взаимодействия.

Хорошо бы объединить наши усилия, чтобы отражать гуманитарные интересы друг друга на общей платформе, удвоив ее мощь и используя креативные возможности молодых пользователей, объявив конкурс на создание студенческих IT-стартапов.

Вместе - мы великая сила, в основе которой взаимное притяжение, которое ярко описал поэт В.В. Маяковский:

$$
\begin{gathered}
\text { Я хотел бы } \\
\text { жить } \\
\text { и умереть в Париже, } \\
\text { если } 6 \text { не было } \\
\text { такой земли - } \\
\text { Москва. }
\end{gathered}
$$


prennent que chaque langue est liée à des scénarios intellectuels qui mènent à des découvertes surprenantes, décisives pour toute l'humanité. Personne n'a encore percé le secret du génie français et russe de la science, de la musique et de l'art, leur intrication et leur compréhension mutuelle.

Hier à l'Université de Moscou, au congrès international consacré aux codes culturels une idée intéressante a été formulée : l'intelligence artificielle sera elle aussi orientée selon un vecteur national parce qu'elle reflètera le code culturel de son créateur.

L'intérêt pour l'intelligence artificielle, l'organisation d'un espace scientifique et d'enseignement à l'aide de l'anglais - linqua franca - constitue pour le classement des établissements universitaires une obligation de publier les résultats de leurs recherches scientifiques en anglais, tout cela mène à un appauvrissement du paysage culturel et linguistique de la Terre et de la pensée scientifique, dont le créateur est l'intelligence naturelle de l'homme. L'expérience du Japon mérite d'être prise en exemple : tous les articles scientifiques majeurs sont d'abord publiés en japonais dans des publications japonaises.

Je note, d'ailleurs, que la gallomanie du premier tiers du XIXe siècle nous a légué un style épistolaire raffiné et étendu : «l'âge d'or de la littérature russe », et la linqua franca pour l'instant ne fait que souiller la langue russe d'emprunts injustifiés.

C'est avec amertume que j'attire l'attention des participants russes sur le fait qu'il faut parfois assister à des conférences tenues sur le territoire de la Fédération de Russie avec pour langue de travail un mauvais anglais.

La Russie et la France doivent unir leurs efforts pour montrer instamment au monde la nature commerciale de la mondialisation, se servir des plateformes d'enseignement et de formation pour populariser le français et le russe dans l'espace linguistique macrosociologique, recourir plus largement aux possibilités de numérisation afin d'élever la motivation des jeunes pour l'étude de nos langues réciproques.

L'expérience des bibliothèques françaises et des pages de Gallica sur le site du Congrès des États-Unis proposant un accès gratuit à la littérature en français devrait attirer l'attention des participants russes.

En 2000 a été fondé le réseau francophone international de construction linguistique pour le développement des contenus en français sur internet. Nous avons également des projets de ce type qui visent à l'expansion des contenus en russe sur internet et c'est une orientation de coopération très intéressante.

Il serait bon d'unir nos efforts pour refléter nos intérêts mutuels en matière de sciences humaines sur une plateforme commune, en doublant sa puissance et en utilisant les possibilités originales des jeunes utilisateurs en organisant des concours autour de la création de start-up d'étudiants dans le domaine des hautes technologies.

Ensemble nous sommes plus fort, et notre force repose sur un attrait mutuel magnifiquement décrit par le poète Vladimir Maïakovsky :

$$
\begin{gathered}
\text { Je voudrais } \\
\text { vivre }
\end{gathered}
$$$$
\text { s'il n'y avait pas }
$$

et mourir à Paris

cette terre : 